\title{
Prevalence and pattern of anaemia and correlation with booking status in a new Medical College in Haryana, India
}

\author{
Anshika Kashyap*, Tabassum Bano, Nadia Babar
}

\begin{abstract}
Department of Obstetrics and Gynecology, Al Falah School of Medical Science and Research Centre, Dhauj,
\end{abstract} Faridabad, Haryana, India

Received: 30 June 2019

Revised: 03 July 2019

Accepted: 08 July 2019

\section{*Correspondence:}

Dr. Anshika Kashyap,

E-mail: dranshika76@gmail.com

Copyright: () the author(s), publisher and licensee Medip Academy. This is an open-access article distributed under the terms of the Creative Commons Attribution Non-Commercial License, which permits unrestricted non-commercial use, distribution, and reproduction in any medium, provided the original work is properly cited.

\begin{abstract}
Background: Anaemia is the commonest medical disorder in pregnancy. It is a leading cause of maternal morbidity and mortality. This study analyses the prevalence and pattern of anaemia and correlates it with booking status in a new medical college in rural Haryana.

Methods: This retrospective study was conducted to analyze prevalence, severity and morphology of anaemia in hospitalized pregnant patients at the time of labour in a new medical college in rural Haryana. Antenatal booking status was correlated with haemoglobin levels and severity. The study was conducted over a period of six months from Nov'18 to April'19.

Results: 390 singleton labour patients at or near term with no other known medical complications were evaluated. Prevalence of anaemia in the centre serving as a referral with onsite blood bank facilities was as high as $79.7 \%$. $47.9 \%$ of patients did not have even a single antenatal visit. 50.8\% had microcytic hypochromic anaemia followed by $32.3 \%$ who had normal morphological picture; dimorphic was $14 \%$ and macrocytic $2.8 \%$. The prevalence in booked patients was $78.91 \%$ compared to $80.1 \%$ in unbooked.

Conclusions: Anaemia continues to be a major challenge to the obstetric services despite targeted efforts by the government and various organizations to provide free prophylaxis. Iron deficiency or nutritional anaemia is the commonest. However, booking visits, counselling and free distribution of iron tablets doesn't ensure that the patient is protected from anaemia. This raises concerns about compliance and hence effectiveness of oral iron therapy. An aggressive strategy for diagnosis, prophylaxis and treatment of anaemia as well as a method to ensure compliance must be developed.
\end{abstract}

Keywords: Anaemia, Booking status, Labour, Morphological typing

\section{INTRODUCTION}

Anaemia in pregnancy continues to be a leading cause of maternal morbidity and mortality worldwide. WHO estimates that $35 \%-75 \%$ ( $56 \%$ on average) of pregnant women in developing countries and $18 \%$ from industrialized countries are anaemic. ${ }^{1}$ Anaemia is estimated to be primarily responsible for $20 \%$ deaths worldwide. ${ }^{2}$ Nutritional or iron deficiency anaemia is most common cause of anaemia during pregnancy, globally affecting at least half of women in middle and low income countries and about 32 million women globally. ${ }^{3,4}$ The corrective measures are simple and effective if appropriately implemented and compliance ensured.

India was the first country to launch the National Nutritional Anaemia Prophylaxis Programme in 1973 
which was later integrated into Reproductive and Child Health programme. In this initiative, pregnant women were administered $100 \mathrm{mg}$ of elemental iron along with $0.5 \mathrm{mg}$ folic acid. ${ }^{5}$ However, India continues to report higher prevalence of anaemia amongst all countries. ${ }^{6}$ Anaemia is the second leading cause of maternal mortality in India and contributes to $80 \%$ of maternal deaths in South Asia. ${ }^{7,8}$

It was noted that though a sizeable number of antenatal patients reported for booking ultrasounds and checks, they failed to follow-up and a large number thereafter reported only at the time of commencement of labour pains. This study intends to identify the prevalence of the problem, study the morphological pattern as well as highlight the importance of more effective measures to ensure compliance amongst patients by comparing the incidence of anaemia amongst booked and unbooked patient.

\section{METHODS}

This retrospective study was done on the basis of delivery records and case sheets of patients who presented to the Obstetric unit with labour pains over a period of six months from November 18 to April 19. The study was conducted in Al Falah hospital, a newly setup medical college in rural Haryana. 390 patients' records were studied. Only singleton pregnancies were included. Exclusion criteria were multiple pregnancies, patients presenting to the unit with acute haemorrhage, women with chronic medical conditions or obstetric conditions like antepartum haemorrhage, preeclampsia which could alter Haemoglobin levels due to the disease condition. Haemoglobin levels measured at the time of admission just before delivery were noted. Haemoglobin was categorised as mild anaemia (10-10.9 g/dl), moderate (7$9.9 \mathrm{~g} / \mathrm{dl})$ and severe anaemia $(<7 \mathrm{~g} / \mathrm{dl})$ according to WHO criteria. ${ }^{9}$ All patients identified as anaemic were routinely subjected to peripheral smear for typing of anaemia as per institute's protocol. After collection of data, the smear results were classified as microcytic hypochromic, normocytic normochromic, dimorphic and macrocytic. Patients who had a single visit to a health facility with investigations and ultrasound were classified as booked. Patients who had never visited any health facility throughout antenatal period were categorized as unbooked. The haemoglobin levels of both these category of patients with morphological typing in cases of anaemia were compared. Frequencies and percentages with mean were calculated to assess variables like age, parity, booked and unbooked status, degree of anaemia and type of anaemia.

\section{RESULTS}

This study included patients admitted with labour pains over a period of six months from Nov 2018 to April 2019. 390 patients who fulfilled inclusion and exclusion criteria were studied.

Table 1: Distribution among the cases for haemoglobin $(\mathrm{gm} \%)$.

\begin{tabular}{|lll|}
\hline Grade of anaemia & No. of cases & Percentage \\
\hline Severe anaemia & 55 & $14.1 \%$ \\
\hline Moderate anaemia & 174 & $44.6 \%$ \\
\hline Mild anaemia & 82 & $21.0 \%$ \\
\hline Normal haemoglobin & 79 & $20.3 \%$ \\
\hline Total & 390 & $100.0 \%$ \\
\hline
\end{tabular}

Table 2: Association amongst cases among haemoglobin and deficiency type.

\begin{tabular}{|c|c|c|c|c|c|c|c|c|c|c|}
\hline \multirow[t]{2}{*}{ Type } & \multicolumn{2}{|c|}{$\begin{array}{l}\text { Hypochromic } \\
\text { microcytic }\end{array}$} & \multicolumn{2}{|c|}{ Dimorphic } & \multicolumn{2}{|c|}{ Macrocytic } & \multicolumn{2}{|c|}{$\begin{array}{l}\text { Normocytic } \\
\text { normochromic }\end{array}$} & \multicolumn{2}{|c|}{ Total } \\
\hline & $\mathbf{N}$ & $\%$ & $\mathbf{N}$ & $\%$ & $\mathbf{N}$ & $\%$ & $\mathbf{N}$ & $\%$ & $\mathbf{N}$ & $\%$ \\
\hline Severe anaemia & 51 & 32.3 & 2 & 4.5 & 0 & 0.0 & 0 & 0.0 & 53 & 17.0418 \\
\hline Moderate anaemia & 79 & 50.0 & 33 & 75.0 & 6 & 66.6 & 22 & 22.0 & 140 & 45.0161 \\
\hline Mild anaemia & 28 & 17.7 & 9 & 20.5 & 3 & 33.4 & 78 & 78.0 & 118 & 37.9421 \\
\hline Total & 158 & 50.8 & 44 & 14.1 & 9 & 2.9 & 100 & $32.2 \%$ & 311 & 100 \\
\hline \multicolumn{2}{|l|}{ Chi-Square Test } & \multicolumn{3}{|l|}{ Value } & df & p-value & \multicolumn{4}{|c|}{ Association is- } \\
\hline \multicolumn{2}{|l|}{ Pearson Chi-Square \$ } & \multicolumn{3}{|l|}{129.41} & 6 & $1.00 \mathrm{E}-04$ & \multicolumn{4}{|c|}{ Significant } \\
\hline \multicolumn{2}{|c|}{ Pearson Chi-Square \# } & 80.133 & & & 2 & 0.0001 & \multicolumn{4}{|c|}{ Significant } \\
\hline
\end{tabular}

$\mathrm{N}$ stands for number. $\$ 5$ cells $(41.7 \%)$ have expected count less than $5 . \wedge$ Column data pooled and Chi-Square Test reapplied

Multigravidas were $74.4 \% \quad(290 / 390)$ whereas primi gravidas were $25.6 \%$ (100/390). Age of patients was in range of 18 to 45 with mean of 25.33 years. Booked versus unbooked patients were $52.1 \%$ and $47.9 \%$ respectively. Thus, 203 patients were booked and 187 unbooked. Prevalence of anaemia was $79.7 \%$ (311 out of
390). Percentages of mild, moderate and severe anaemia were $21 \%, 44.6 \%$ and $14.1 \%$ respectively. $20.3 \%$ had normal Haemoglobin levels. Morphological typing of anaemia showed microcytic, hypochromic pattern to be the commonest (158 patients i.e. 50.8\%); followed by normocytic, normochromic (100 patients i.e. 32.1\%). 
$14 \%$ patients (44/311) had dimorphic and $2.9 \%$ (9 patients) had macrocytic anaemia on morphological typing in peripheral smear. There were $78.91 \%$ of booked patients were found to be anaemic. There were $80.7 \%$ unbooked patients were anaemic. The mean haemoglobin in booked patients was $9.27 \mathrm{~g} / \mathrm{dl}$ whereas in unbooked patients it was $9.07 \mathrm{~g} / \mathrm{dl}$. Booked patients thus had only marginally better Haemoglobin levels, an association which was statistically insignificant. The booked cases showed $41.9 \%$ incidence of moderate, $23.2 \%$ mild anaemia and $13.8 \%$ severe anaemia against a corresponding $47.6 \%, 18.7 \%$ and $14.4 \%$ in the unbooked patients. The association was not significant thus indicating that booking or antenatal visits didn't ensure prevention of anaemia or better haemoglobin levels.

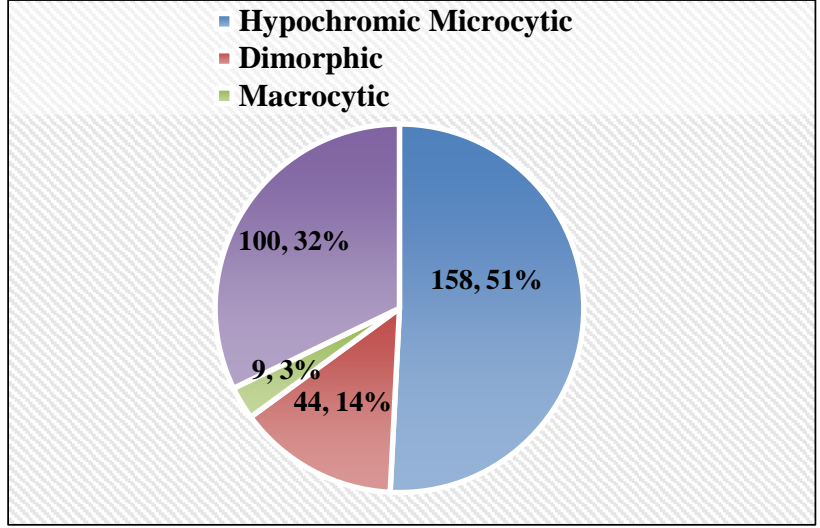

Figure 1: Types anemia with distribution.

Table 3: Association among the cases between haemoglobin (gm\%)* booked status.

\begin{tabular}{|c|c|c|c|c|}
\hline \multirow{2}{*}{ Haemoglobin (gm\%) } & \multicolumn{3}{|c|}{ Booked status } & \multirow{2}{*}{ Total } \\
\hline & & Booked & Unbooked & \\
\hline \multirow{2}{*}{ Severe anaemia } & No. & 28 & 27 & 55 \\
\hline & $\%$ & $13.8 \%$ & $14.4 \%$ & $14.1 \%$ \\
\hline \multirow{2}{*}{ Moderate anaemia } & No. & 85 & 89 & 174 \\
\hline & $\%$ & $41.9 \%$ & $47.6 \%$ & $44.6 \%$ \\
\hline \multirow{2}{*}{ Mild anaemia } & No. & 47 & 35 & 82 \\
\hline & $\%$ & $23.2 \%$ & $18.7 \%$ & $21.0 \%$ \\
\hline \multirow{2}{*}{ Normal hemoglobin } & No. & 43 & 36 & 79 \\
\hline & $\%$ & $21.2 \%$ & $19.3 \%$ & $20.3 \%$ \\
\hline \multirow{2}{*}{ Total } & No. & 203 & 187 & 390 \\
\hline & $\%$ & $100.0 \%$ & $100.0 \%$ & $100.0 \%$ \\
\hline Chi-square test & Value & df & p-value & Association is- \\
\hline Pearson chi-square & 1.833 & 3 & 0.608 & Not significant \\
\hline
\end{tabular}

\section{DISCUSSION}

The hospital provides delivery services free of cost to low socioeconomic strata. Most of patients have minimal to no formal education. It is obvious from our study that many patients present to the hospital only at the time of delivery. This study showed an incidence of $52.1 \%$ booked versus $47.9 \%$ unbooked patients. This is better than a study by Singh et al which showed a $15.3 \%$ of booked and $84.7 \%$ unbooked case at the time of presentation in labour. ${ }^{10}$ Lack of antenatal care represents a missed opportunity for diagnosis, prophylaxis, treatment and counselling of the patients.WHO reported $35 \%$ to $75 \%$ (56\% on average) of pregnant women in developing countries are anaemic. ${ }^{2}$ In this study, the prevalence of anaemia in labouring patients was $79.7 \%$. Babita Bansal et al, reported a prevalence of anaemia in second and third trimester of pregnancy to be $84 \% .{ }^{11}$ The very high prevalence could be due to the presence of blood bank in the centre under study which receives a large number of referrals from the nearby $\mathrm{PHC}$ on account of anaemia. It can also be attributed to the low socioeconomic status and poor education levels of the patients. This study showed the highest prevalence of moderate anaemia $44.6 \%$, followed by mild $21 \%$ and then severe anaemia $14 \% .20 .3 \%$ patients in this study had normal haemoglobin levels. Rawat et al, in their study too showed a higher prevalence of moderate anaemia $51.3 \%$, mild $35.1 \%$ and severe $13.4 \% .^{12}$ However the study by Rawat et al, had only included anaemic patients and categorised them accordingly. Tyagi $\mathrm{N}$ et al, reported a higher prevalence of moderate anaemia $61 \%$ followed by $29.5 \%$ of mild anaemia. ${ }^{13}$ The incidence of severe anaemia in our study was similar to the $14.3 \%$ and $14 \%$ incidence observed by Bansal B et al, and Wanjari SA et al, in their respective studies. ${ }^{11,14}$ However, another study by Singhal et al, showed $5.7 \%$ prevalence of severe anaemia. ${ }^{15}$ The identification of severe anaemia is important as all such patients potentially need cross match on admission and hence must be delivered in a centre where access to blood transfusion is available. This group of patients are likely be subjected to blood transfusions with all its associated difficulties and hazards. 
This study showed morphologically a $50.8 \%$ incidence of microcytic hypochromic anaemia, $32.1 \%$ of normocytic normochromic anaemia, 14\% dimorphic anaemia and lastly $2.9 \%$ macrocytic anaemia. A study by Rawat et al, similarly showed microcytic hypochromic anaemia to be the commonest at $51 \%$ followed by $32 \%$ normocytic normochromic anaemia, $13 \%$ dimorphic and $4 \%$ macrocytic. $^{12}$ All these indicate that iron deficiency anaemia is the main challenge to the antenatal services. The incidence of anaemia was $78.9 \%$ in booked and $80.7 \%$ in unbooked patients. The mean Haemoglobin levels in booked and unbooked patients were also 9.27 $\mathrm{g} / \mathrm{dl}$ and $9.07 \mathrm{~g} / \mathrm{dl}$ that were statistically insignificant. Booking status thus didn't result in lower anaemia rates. Singh et al reported that unbooked patients had more anaemia in their study. ${ }^{10}$ The centre offers iron tablets free of charge and ensures proper counselling to all antenatal patients at booking visits regarding nutrition and importance of anaemia prophylaxis. This reflects that merely increasing antenatal care attendance doesn't translate to lower anaemia rates. A more intense and effective strategy to ensure better compliance in the form of direct observed, supervised therapy or injectable iron maybe a more effective measure. Vindhya et al, in their study emphasized that it is important to consider and address other factors when designing and implementing target interventions for anaemia control in selected populations. ${ }^{16}$

In India, the prevalence of anaemia in adolescent girls is $56 \% .{ }^{17}$ Various studies in Vadodara, Tamil Nadu, and West Bengal across all geographical parts of India have shown $75 \%, 44.8 \%, 45 \%$ prevalence of anaemia in adolescent girls. ${ }^{18-20}$ Thus, a large number of patients are anaemic at the onset of pregnancy itself. This gets compounded by repeated childbearing, lack of contraception, poor education and apathy. Mere preventive prophylaxis under NNAPP can't solve the problem. The Government of India in 2013 introduced national implementation of weekly iron and folic acid supplementation to approximately 120 million adolescent girls taking cognizance of the vast problem. ${ }^{21}$ Various other measures like fortification of food and rations, incentives to ASHA workers and ensuring accountability for service providers of free tablets, supervised therapy etc. must be explored.

Funding: No funding sources Conflict of interest: None declared

Ethical approval: The study was approved by the Institutional Ethics Committee

\section{REFERENCES}

1. WHO: The global prevalence of anaemia in 2011. Geneva: World Health Organization, 2015. Available at:

https://apps.who.int/iris/bitstream/handle/10665/177 094/9789241564960_eng.pdf;jsessionid=57AB1E77 C9AFD1DA6FD1811C1D727605? sequence $=1$.
2. Viveki RG, Halappanavar AB, Viveki PR, Halki SB, Maled VS, Deshpande PS. Prevalence of anaemia and its epidemiological determinants in pregnant women. Al Ameen J Med Sci. 2012; 5(3):216-23.

3. Balarajan Y, Ramakrishnan U, Ozaltin E, Shankar A, Subramanian S. Anaemia in low income and middle income countries. Lancet. 2011;378(9809):2123-35.

4. Stevens G, Finucane M, De- Regil L, Paciorek C, Flaxman S, Branca $\mathrm{F}$ et al. Global, regional and national trends in children and pregnant and nonpregnant women for 1995- 2011: A systematic analysis of population- representative data. Lancet Glob Health. 2013;1(1);e16-e25.

5. Ministry of Health and Family Welfare. Guidelines for Control of Iron Deficiency Anaemia. Nhm. Gov.in;2013. Available at: http://nhm.gov.in/nrhmcomponents/ rmnch-a/ child-health- immunisation/ child- health/ guidelines.html.

6. Ezzati M, Lopez A, Rodgers A, Vander Hoorn S, Murray C. Selected major risk factors and global and regional burden of disease. Lancet. 2002;360(9343):1347-60.

7. Ramachandran $\mathrm{P}$, Kalaivani $\mathrm{K}$. Time trends in prevalence of anaemia in pregnancy. Indian $\mathrm{J}$ Med Res. 2018;147(3):268.

8. Kalaivani K. Prevalence and consequences of anaemia in pregnancy. Indian $\mathrm{J}$ Med Res. 2009;130(5):627-33.

9. WHO Haemoglobin concentration for diagnosis of anaemia and assessment of severity. Vitamin and Mineral Nutrition Information System. Geneva 2011. Available at: http://www.who.int/vmnis/indicators/haemoglobin.p df.

10. Singh S, Kaur K. Maternal outcome in cases of severe anaemia in labour. Int $\mathbf{J}$ Reprod Contracept Obstet Gynecol. 2018;7(3):1201-4.

11. Bansal B, Takkar J, Kumaragarwal D, Agarwal S. Comparative study of prevalence in Muslim and nonMuslim pregnant women of Western Rajasthan. Intern J Res Health Sci. 2013;1(2):47-52.

12. Rawat K, Rawat N, Mathur N, Mathur M, Chauhan N, Kakkar R, et al. Prevalence and pattern of anemia in the second and third trimester pregnancy in Western Rajasthan. Int J Res Med Sci. 2016;4(11):4797-9.

13. Tyagi N. Prevalence type and severity of anemia in antenatal cases in a tertiary care hospital in North India. ANN Woman and Child Health. 2016;2(1):A7-10.

14. Wanjari SA. Evaluation of anaemia in pregnant women. J Evidence Based Med and Healthcare. 2014;1(8):1085-9.

15. Singhal SR, Nanda S. Maternal and perinatal outcome in severe anaemia. Indian Practitioner. 2007;60(11):691-4.

16. Vindhya J, Nath A, Murthy GV, Melgrid C, Sheeba $\mathrm{B}$, Shubashree V et al. Prevalence and risk factors of anaemia among pregnant women attending a public 
sector hospital in Bangalore, South India. India J Family Med Prim Care. 2019;8(1):37-43.

17. Aguayo VM, Paintal K, Singh G. The adolescent girls' anaemia control programme: a decade of programming experience to break intergenerational cycle of malnutrition in India. Public Health Nutr. 2013:16(9):1667-76.

18. Koetcha PV, Nirupam S, Karkar PD. Adolescent girls' anaemia control programmed, Gujarat, India. Indian J Med Res. 2009;130(5):584-9.

19. Rajaratnam J, Abel R, Asokan JS, Jonathan P. Prevalence of anaemia among adolescent girls of rural Tamil Nadu. Indian Paediatr. 2000;37(5):532-6.
20. Das PK, Biswas R. Nutritional status of adolescent girls in a rural area of North Parganas district, West Bengal. Indian J Public Health. 2005:49(1):18-21.

21. The Adolescent Girls Anaemia Control Programme. Breaking intergenerational cycle of under nutrition in India with a focus on adolescent girls. New York: United Nations Children' Fund: 2011. Available at: http://www.unicef.org/india/14. Adolescent Anaemia Control Programme.pdf.

Cite this article as: Kashyap A, Bano T, Babar N. Prevalence and paftern of anaemia and correlation with booking status in a new medical college in Haryana, India. Int J Reprod Contracept Obstet Gynecol 2019;8:3056-60. 